University of Wollongong

Research Online

Faculty of Business - Papers (Archive)

Faculty of Business and Law

2012

Tourism in technology dead zones: documenting experiential dimensions

Philip Pearce

James Cook University

Ulrike Gretzel

University of Wollongong, ugretzel@uow.edu.au

Follow this and additional works at: https://ro.uow.edu.au/buspapers

Part of the Business Commons

Research Online is the open access institutional repository for the University of Wollongong. For further information contact the UOW Library: research-pubs@uow.edu.au 


\title{
Tourism in technology dead zones: documenting experiential dimensions
}

\begin{abstract}
In the last decade, the way tourists use communication technology has become a strong focus of tourism research. Nevertheless there are some locations where there is limited or no internet technology access. These locations can be labeled dead zones. The aims of the present research focus on how tourists think about and react to situations where their normal connectivity with their larger social and information world is disrupted. This study uses the results from five focus groups as well as considerable supporting literature to map the kinds of experiential outcomes tourists report when they are in dead zones. The work reviews tourists' positive and negative experiential outcomes arising from operating outside of their usual technology support systems. In particular the study found that there are major tensions arising from dead zone tourism; specifically stress related to social communication, work communication, safety versus escape, and refreshing or learning the skills of being fully engaged with the present company and setting.
\end{abstract}

\section{Keywords}

experiential, dimensions, tourism, technology, dead, zones, documenting

\section{Disciplines}

Business

\section{Publication Details}

Pearce, P. \& Gretzel, U. (2012). Tourism in technology dead zones: documenting experiential dimensions. International Journal of Tourism Sciences, 12 (2), 1-20. 
Tourism in technology dead zones; documenting experiential dimensions

Philip L. Pearce

James Cook University, Townsville, Queensland, Australia

and

Ulrike Gretzel

University of Wollongong, Wollongong, New South Wales Australia 


\begin{abstract}
:
In the last decade, the way tourists use communication technology has become a strong focus of tourism research. Nevertheless there are some locations where there is limited or no internet technology access. These locations can be labelled dead zones. The aims of the present research focus on how tourists think about and react to situations where their normal connectivity with their larger social and information world is disrupted. This study uses the results from five focus groups as well as considerable supporting literature to map the kinds of experiential outcomes tourists report when they are in dead zones. The work reviews tourists' positive and negative experiential outcomes arising from operating outside of their usual technology support systems. In particular the study found that there are major tensions arising from dead zone tourism; specifically stress related to social communication, work communication, safety versus escape, and refreshing or learning the skills of being fully engaged with the present company and setting.
\end{abstract}

Keywords; tourism technology, dead zones, experiential outcomes, digital elasticity, thresholds, technology-induced tension 


\section{INTRODUCTION}

"The future of travel ... lies in 'black-hole resorts', which charge high prices precisely because you can't get online in their rooms" (The New York Times, January 1, 2012).

Both everyday lives and vacations are to an increasing extent mediated by technology (Tussyadiah \& Fesenmaier, 2009). The rising penetration of vacation time by technology is due to the presentation and communication power of the technologies but it is also driven by a spill-over of relationships and technology use demands from everyday life (Ryan, 2002; White \& White, 2007). It can be suggested that the desired benefits of a vacation might not be realized if such spill-over happens. While some tourists might be motivated to restrict technology use during vacations, others might need to experience specific settings to be able to overcome their technology dependence.

Even in developed nations several locations still exist in regional and remote areas where the use of new technology based communication tools are out of reach. These areas can be labelled dead zones. It is proposed here that dead zones might be important facilitators of positive tourism experiences, although the possibilities for stress arising from being disconnected also exist. Dead zones may force technology dependent tourists to temporarily abandon their fully wired everyday lives and immerse themselves in an "unplugged" tourism experience. No research currently exists that has looked at the potential impacts of dead zones on wellbeing, and especially not in tourism. While the impacts of technology use are increasingly studied in the tourism context (Gretzel, 2010), the consequences of externally motivated lack of use or conscious choice of dead zone settings to control use have not even been considered. The aims of this research are to outline how tourists think about and react to destination settings where their normal connectivity with their larger social and information world is disrupted.

\section{LITERATURE REVIEW}


The new technology based connections between the home base and the holiday setting challenge long established models of the way tourists derive value from their vacations. In the traditional view of a vacation, tourists cross a threshold which disconnects them from their home world and plunges them into an often rewarding, sometimes transformative and occasionally challenging space (Hottola, 2004). The concept of the ritual crossing of a threshold has been formative in shaping much tourism research thinking (van Gennep, 1960; Turner \& Turner 1978; Graburn, 1989; van Egmond, 2007). This is illustrated in the first part of Figure 1. Pearce (2011) suggests that tourist experiences should no longer be seen as defined in this way but rather now have to be understood as involving ongoing connections which render everyday life and vacation time mutually influential (second part of Figure 1). The term employed to describe this new blurring of space is "digital elasticity" which is defined as tourists remaining electronically linked to their home worlds as they explore their identity and the worlds of others (Pearce, 2011: 41). For example, tourists check their emails while sipping a cocktail at the pool, friends and family comment on recently posted mobile photo uploads on Facebook, international tourists play web based games with friends across continents, and work emails are monitored for office based crises. All of these activities may distract tourists from their immediate holiday settings. It is often hard for tourists to control such technology use, either because of social obligations or because of addictions to the technology (Turel et al., 2011). Vacations are supposed to provide relaxation and time away from work but it is questionable as to whether they can still provide such important escape experiences (see Salon.com, 2010 article entitled: "No more vacation: How technology is stealing our lives"). Indeed, technology is now often necessary to facilitate tourism experiences and to "eliminate some of the socio-cultural friction of touristic mobility" (Jansson, 2007:13). However, once the technology is switched on as one element of the vacation experience, it is likely to be used beyond immediate holiday purposes.

The central concerns of this paper involve identifying a third kind of space - the dead zone which is also depicted In Figure 1.Due to factors such as difficult terrain and dispersed populations, both of which increase the costs of providing reliable connections, many remote and regional areas can be described as technological dead zones. For tourists visiting these locations the dead zones serve as important barriers between the everyday and the tourist experience. Both positive and negative affective and cognitive consequences for the tourist experience can be predicted. The thought of not being able to connect when such needs arise 
might lead to severe anxiety (Grüsser, et al., 2005; Turel et al., 2011). Additionally those with a high level of technology addiction may also be dissatisfied in such "unplugged" environments (Porter \& Kakabadse, 2006; Joyce, 2008; Shu et al., 2011). Nevertheless a more positive reaction can also be anticipated. Without the distractions caused by the technological connections, tourists may be able to focus more directly and consistently on their immediate surroundings and relationships. They might even be encouraged to engage in activities and behaviours reminiscent of those once enjoyed in the days when vacations were clearly threshold crossing events.

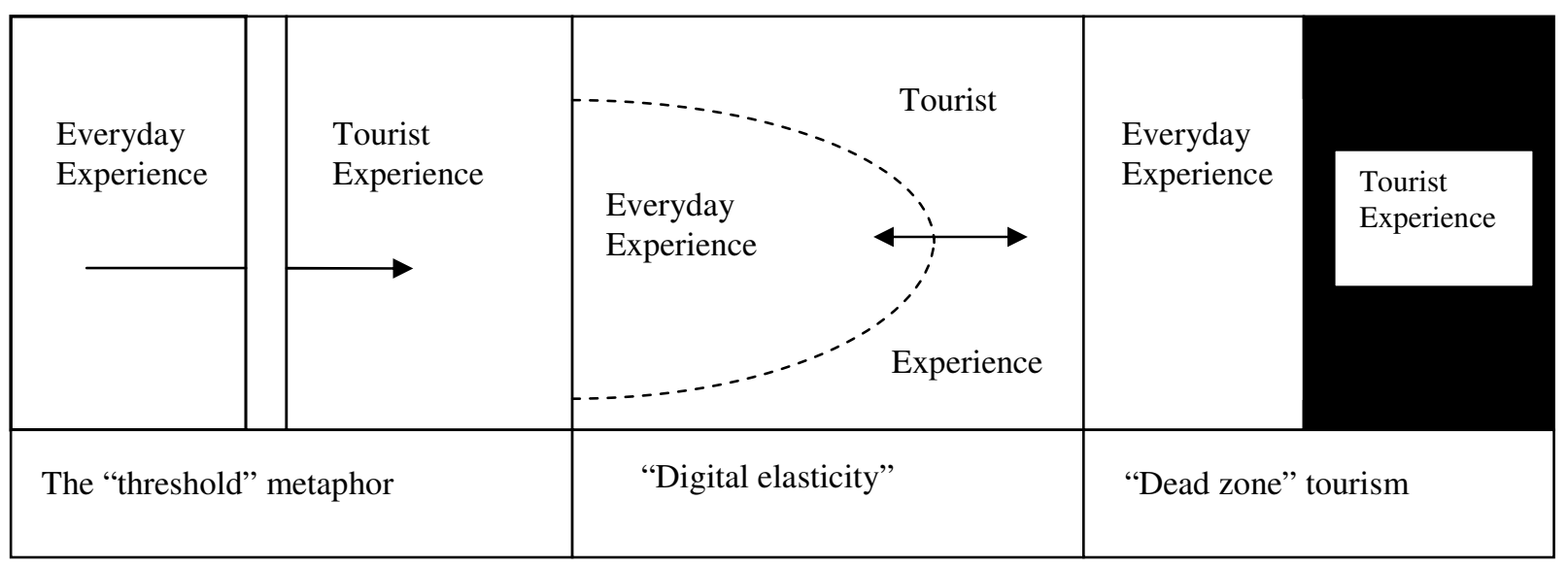

Figure 1 Changing conceptions of tourists' connections to their home base

The analysis of tourists' reactions to being in dead zones requires a considered assessment of previous work on measuring experiences. While there is clearly a focus on experiences in tourism research dating from formative studies by Cohen (1979) and Krippendorf (1987), many older empirical research efforts have a very narrow and/or outdated view of experiences, taking only into account a basic consideration of satisfaction. Criticisms and reviews of these earlier efforts are available in Ryan (1995, 2000), Noe (1999), Kozak (2001) and Morgan et al. (2010). Promising new approaches to experience measurement include rich assessments of consumption emotions, skill development, and changes in time perspectives (Filep, 2012). Some of these fresh approaches derive from work in positive psychology which resonates in a rich and rewarding way with tourism study since the wellbeing and happiness of individuals are core and common concerns (Seligman et al., 2005; Diener \& Biswas-Diener, 2008; Langer, 2009). There is, though, an overriding issue which must be addressed before experience assessment can be more completely integrated into the mind sets and working approaches of tourism researchers. The issue is that of the 
comprehensiveness and validity of the experience assessment. The issue can be broken down into two reinforcing streams of thought.

In approaching new topics and in developing measures there has been a long standing tradition amongst qualitative researchers that an emic approach should be employed. The ideas derive from Pike (1967), an anthropologist and linguist. An emic point of view results from studying behaviour from inside a system. The contrasting perspective is referred to as an etic strategy and examines behaviour from outside a particular system. These two approaches can also be labelled top down and researcher imposed (equivalent to etic) and bottom up and respondent driven (equivalent to emic). Pike's concept was further elaborated by Berry (1999), Warner (1999), Niblo and Jackson (2004) and other researchers in a wide range of study areas. Cohen (1979) was the first researcher in tourism to advocate the emic approach. He argued that it is not sufficient to study the touristic process from the outside, and the emic perspective of the different parties participating in the tourism process should hence be given explicit recognition in the research design. The emic approach stresses using techniques which give participants and respondents the opportunity to approach the topic of interest in such a way that they can express their full range of views and attitudes. This may not occur within an etic framework where the researcher presupposes knowledge of the dominant ways in which tourists will view a topic and therefore, typically uses structured responses and coding schemes. The core ideas underlying an emic approach have been supported by the rise of critical and interpretive paradigms in tourism study (Walle, 1997; DeCrop, 2004; Tribe, 2009; Jennings, 2010). The power and direction given to the present research by adopting an emic approach lies in ensuring that the as yet unknown reactions by tourists to dead zones can be richly described rather than implied from the researchers' judgements.

The emic approach is consistent with recent concerns in social science research that a damaging hegemony has arisen relating to the assessment of human responses to social topics. Rossiter (2011) has argued for some time that researchers have been overly concerned with the reliability of their testing instruments and falsely view statistical indices such as Cronbach alpha, for example, as indicating that their measures are sound. In the world of psychometrics this is an incorrect view as such statistical summary tools report only the 
internal consistency of what has been measured and not its fundamental validity addressing the key phenomenon under study. The views of Rossiter (2011), like those of Gomm (2009), Pisani (2008), Flick (2006) and others who specialise in ensuring that a phenomenon is well captured by the way we ask for information, are consistent with using an emic approach as a first step in exploring reactions to new topics such as dead zone tourism experiences.

A particular challenge of considering experiences in this study is how to summarise and provide a satisfactory view of the term. There are, as already suggested, a number of sound reasons for providing a broad ambit of interests and factors within the experience construct rather than simply focussing on satisfaction. In a recent synthesis Pearce (2011: 2-5), drawing on the rich work of previous authors, suggests that the contributing elements to an orchestrated sense of experience are the sensory inputs, the affective reactions, the cognitive mechanisms used to think about and understand the setting, the behaviours available and the relevant relationships which define the participant's world. In this study the emphasis on experiences will be developed by permitting respondents to describe their activities, attitudes and emotional responses to being in dead zones. The ways in which these records and conversational comments link to the developing world of experience analysis in tourism and leisure studies will be pursued in a post-hoc fashion in the discussion part of the paper rather than assuming that the categories provided in the work of existing authors embrace all of the interest areas which might be unearthed in this somewhat novel and exploratory area of interest.

The central aim of the research, which is informed by these ideas in the literature, lies in exploring how moderate to high level technology users view their tourism experiences in dead zones. In this study design it is important to consider those who use internet and social media technologies relatively often, as while such communication tools are widespread they are not truly evenly spread in their use across any local population (Sigala, 2012). A useful expression here is that the research will consider the experiences of both "digital natives", that is those who have grown up with new technologies, as well as those in a slightly older age bracket who have learned to use and now rely on the technology quite heavily (Gretzel, 2010; Yoo \& Gretzel, 2012). 


\section{METHODOLOGY}

A qualitative research methodology built around a total of five focus groups was selected to investigate the experiential dimensions of being in dead zones. As suggested in the literature review, exploratory work in the field of tourism is well served by adopting an emic and thorough documentation of the themes which matter to the key participants (Jennings, 2010; Phillimore and Goodson, 2005). The emic approach avoids researchers pre-judging the issues of concern to the participants. By way of contrast, strong top down and researcher dominated investigations can be misleading and fail to capture all components of interest when structured response scales and measures are applied to fresh topics of inquiry (Rossiter, 2011). In employing a qualitative research methodology it is appropriate to use a number of carefully designed checks and strategies to maximise the value of the approach (Krueger and Casey, 2000). These components include careful attention to participant recruitment, facilitator consistency, and a well organised procedure to enable much rich information to be generated.

\section{Recruiting participants}

The first three focus groups were held in the region south of Sydney, New South Wales, Australia. The criteria for recruiting participants were that they were moderate to heavy digital communication users and they had some recent travel and holiday experiences. The sample was recruited through a snowball sampling technique starting with personal contacts of the researchers in the region. Facebook posts were of assistance in explaining the purpose of the focus groups which was openly represented to the potential participants as a discussion of the roles of technology in daily life and holidays. Ethics approval for the study was obtained through the University of Wollongong procedures. The Facebook recruitment strategy was congruent with the first requirements for participation -the frequent use of digital communication technologies- as the approach ensured that the focus group participants were very likely to be at least somewhat versed in the use of contemporary communication technology (Prensky, 2001). A checking procedure at the start of all the focus groups, whereby all participants were asked to report on their use of the internet and mobile phones, confirmed this assumption. 
A second filtering requirement for participation was that the potential contributors to the focus group discussion had to have travelled for holiday and leisure purposes within the past two years either within Australia or internationally. All participants met this requirement. Recruiting participants for the fourth and fifth focus groups followed the same procedures but these two groups were held at a later point in time and the questions asked within the group were more refined in terms of the goals of the study. One of these groups was held in the same region south of Sydney, while a further and final set of participants was recruited and the focus group discussion held in the north of the country, specifically in Townsville, northern Queensland, Australia. The value of recruiting this fifth focus group in a different part of Australia was seen as ensuring that local technology availability, which might influence travellers' experiences in dead zones, was considered in the study design.

The coverage map of Australia (Figure 1) reveals that different districts and zones have variable coverage thus potentially exposing those who live in different zones to varying levels of familiarity with the themes of the research. In this context the map representing reliable coverage zones in Australia serves to illustrate regional variability within one country and supports the value of recruiting participants from different areas rather than limiting the scope of the study to one continent. It is important to observe that while the focus of direct work is built on samples from Australia the coverage of tourism dead zone destinations which the respondents described was from a truly international array of settings. 


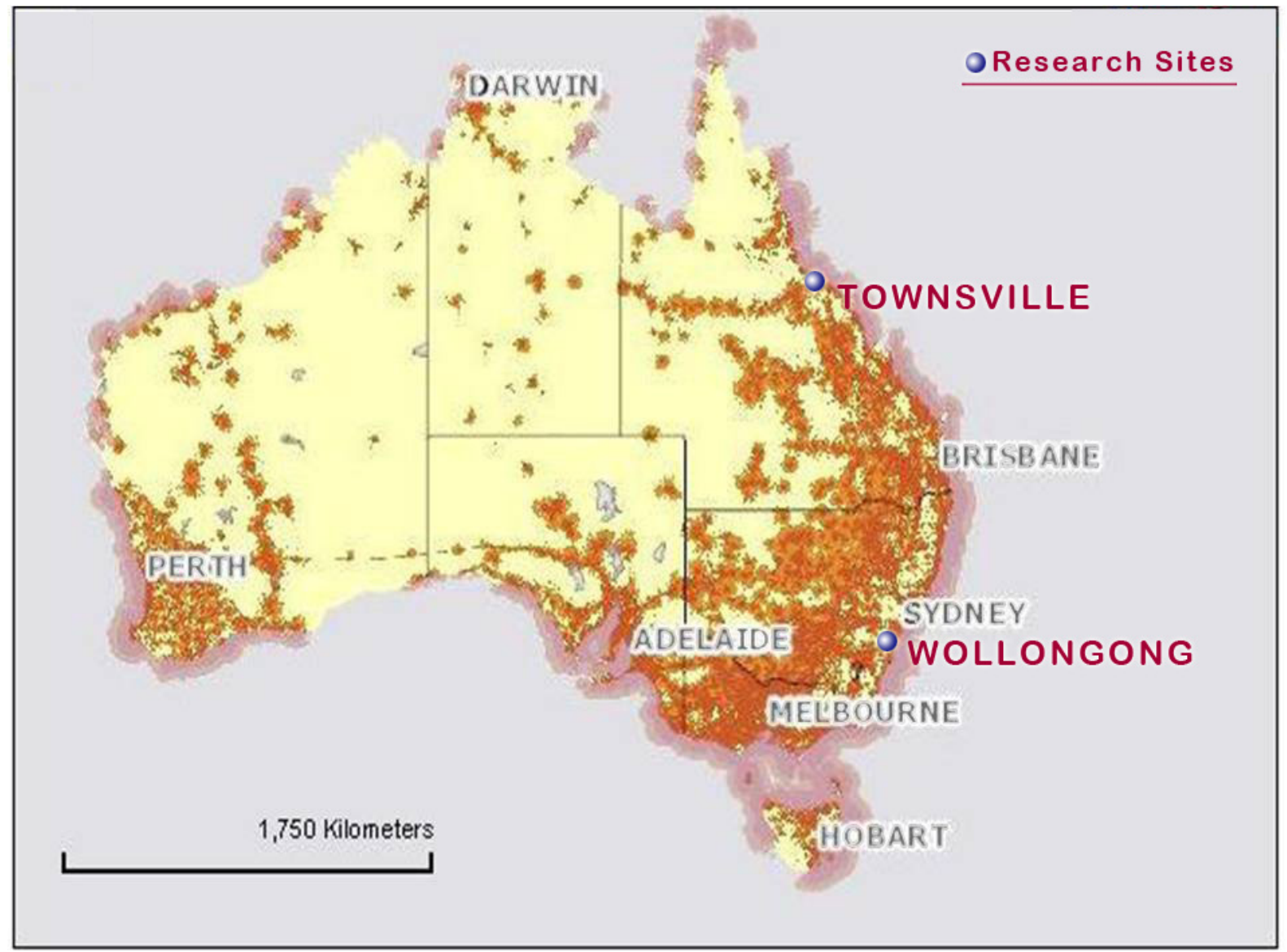

Voice, Picture, TV, Video \& Broadband

Approximate coverage. Coverage speed and perfomance is dicture, TV, Video \& Broadband with an

you are using, and can be improved by adding an external antenna.

Figure 2 Research sites in the context of Australia's digital services.

Thirty seven participants were involved in the 5 groups; 24 were less than 23 years old, 10 were 25-30 years of age and 3 were over 30. Males and females were evenly distributed with 18 males and 19 females. The groups included a small number of high school students (4), while most were professionals (15) and University students (18). As is common in this type of research the defining issue and value of the sample resides not simply in the number of people recruited but their openness and willingness to discuss the topic thus providing the richness of insights required to meet the research goals (De Crop, 2004). The procedural details for the study outline the ways in which these objectives were achieved.

Procedure 
All focus groups were conducted using the best practice procedures recommended by Krueger and Casey (2000) which included non-evaluative comments on respondents' contributions. A feature of the first three focus groups was that the discussion of technology, daily life and digital technology use on holidays was wide ranging. For the last two focus groups a specific treatment of dead zone tourism was the core of the discussion. The management of the groups followed a consistent focus group protocol. The same facilitator conducted the first three sessions while a second facilitator was responsible for the management of the final two focus groups. The discussions lasted for up to 90 minutes and on each occasion the facilitators sought responses to set topics.

More specifically, for the first three groups the topics were the rules for speaking during the focus group interaction, an explanation of the research interest in holidays and technology, regular technology use, and access to information while travelling. The two more specific dead zone tourism focus groups observed a similar structured sequencing of questions. On this occasion the questions considered were everyday technology use, holiday technology use, technology dependence, the advantages and disadvantages of being off-line while on holidays, and the protocols for using technology when with other people. Additionally, at the conclusion of these two focus groups respondents were asked if they could write down one episode or incident involving technology use while on holiday. It was suggested to focus group members that this incident could contain either positive or negative themes.

\section{RESULTS}

The five focus groups discussion and the requests for a written holiday technology episode produced a total of 7.25 hours of recorded conversation, 109 pages of transcribed text and 19 specific holiday technology episodes. Since several portions of the transcripts also featured travellers' stories about their holiday technology experiences, the actual number of episodes can be increased to a total of 25 specific incidents.

The analysis of the material proceeded by reading and re-reading the five texts from the focus groups. The specific experiential dimensions of dead zone tourism were developed by focussing on all focus group contributions as well as reviewing the 25 specific tourism incidents. In common with recommended procedures for the qualitative analysis of material 
of this type, summary themes were developed from the reading and then added to or discarded on further re-reading of the material (Gomm, 2004; Rabiee, 2004). When one researcher had completed this task the second researcher checked and reviewed the adequacy of the summary themes.

The overriding theme identified in this appraisal of respondents' views about being in a dead zone can be represented by the label "technology-induced tension." In essence this term defines the polarities of experience described by respondents when confronted with a dead zone while on holidays. It is comprised of four sub-components: a concern with maintaining social communication while being frustrated by its demands; the issue of staying in touch with work requirements while seeking to escape them; the value of being free and unplugged contrasted with the absence of a safety or security net for troubling events; and the enjoyment of mere presence and a focus on the now while challenged by the skills of participating in the moment. The core ideas defining these issues are presented in Figure 3. 


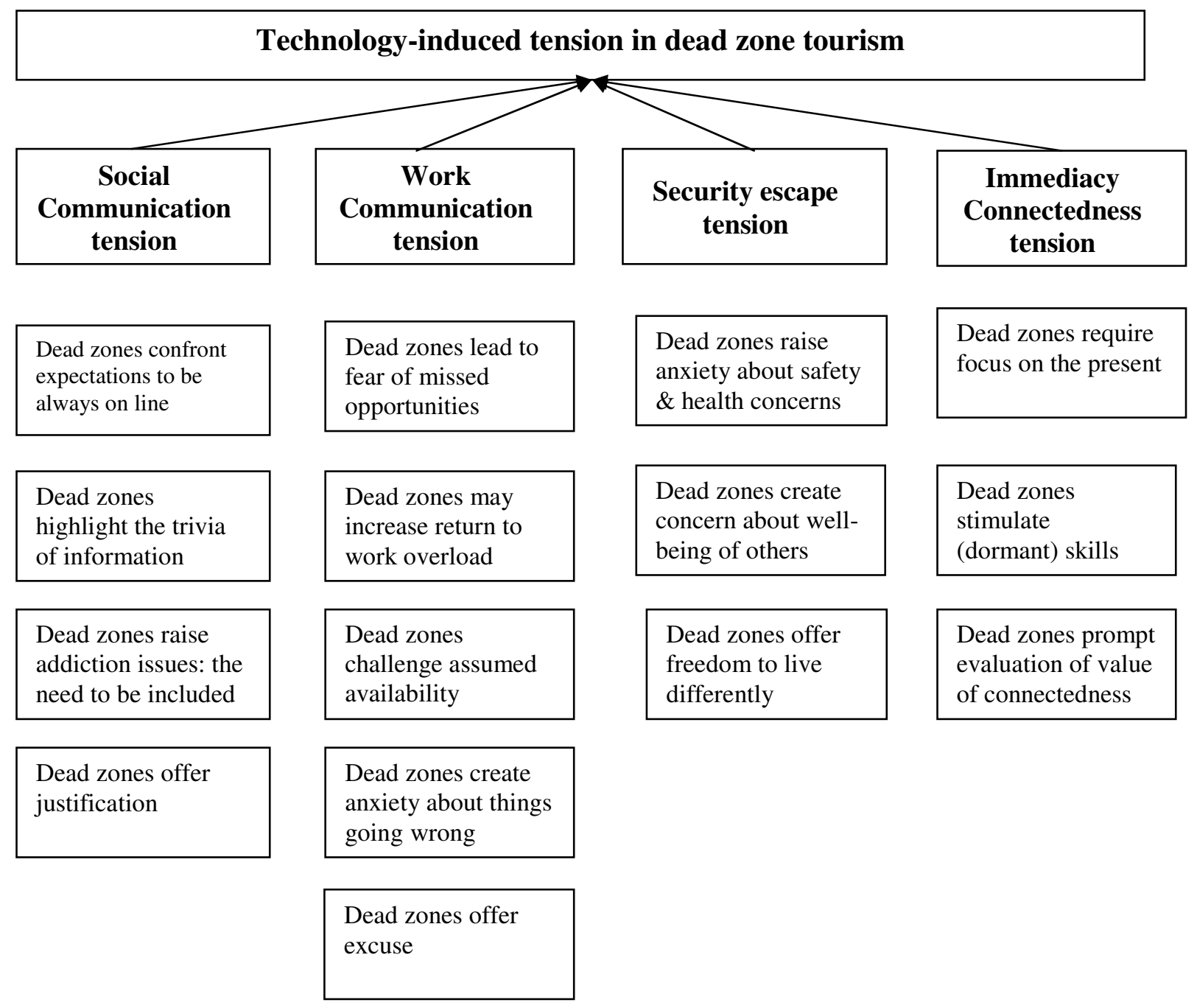

Figure 3 Components of technology-induced tension accompanying tourism time in dead zones

Incidents, phrases and slices of the focus group conversations assist in explaining these subcomponents of technology tension.

Social communication tension: Several respondents expressed the requirements to stay socially connected while also recognising their own somewhat addictive dependence: Mark reported "I find that if I don't have a (working) phone it is an insult to other people." George noted: 'it's like what do you have a mobile for? You are supposed to have it with you (and be 
connected at all times". Hannah observed; “if you aren't on Facebook then you don't know about it, and because of that I feel a dependency to be on it even though I don't enjoy it" Imogen recognised that being without reception in a dead zone was also a positive force: “cool, I don't have to worry about anyone; you worry about it when you get back to the real world, say anything, but it is nice to have that excuse that there is no reception". An element of the social communication concerns was that some respondents highlighted that much of the interchanges in which people appeared to be deeply engaged were often a quite trivial reporting of daily events and activities. Francis observed: "I hate people who update their status every second. I just got up. I just brushed my teeth. And I am thinking nobody cares." This trivialisation of communication prompts its own desire for escape into a dead zone amongst some respondents.

Work communication tension: The reach of digital technology into the holiday space was noted in the literature review where the concept of digital elasticity was considered. Respondents in the focus groups expressed their concerns about this issue when in dead zones. They feared that they might miss an important work development and especially a missed opportunity such as a new job offer. Magda reported: "the only reason I check the email when I am away was because of this place where I work, in case they need you, (but in a dead zone) they think I am not answering." While not personally experiencing the issue, Jane suggested that others would be troubled by work issues in dead zones: "I am not important enough now at the moment where people would be calling me with work hassles. So it is not a real issue although for some people it would be." Importantly even those respondents who mentioned that they indicate to colleagues through messages that they were on holidays and not answering the phone, they still felt the tension that if it was an important issue they would be expected to respond and be monitoring their work world. Again the advantage of being in a dead zone is that it forms a compelling excuse for not paying attention to these pressures.

Security escape tension: The concept of the dead zone threatened many high frequency technology users in terms of being able to access emergency help or meet their needs for safety. Tony noted: "My only concern (of being in a dead zone) is caused when I go to see my family down south. There are long stretches in New South Wales along the way you don't 
get Optus reception. And it is more a concern that you would break down. You wouldn't have access to mobile phone to call any support or any help. We have to rely on somebody actually stopping. I've seen too many movies like Wolf Creek - Australian horror movie about tourists being assaulted - to trust people on outback country roads." For other respondents the concern was less about their actual welfare and more about reporting their well-being to others who might be worried about them. Additionally, checking on the welfare of older relatives was a concern to some respondents. The counter position to these safety concerns is the sense of adventure, spontaneity and freedom embraced by some respondents when effectively unplugged. Susan writing about her time in Slovenia noted: "It was so beautiful...so pristine with no phone reception. Our group split up a little and we could not find one another. It felt good that I could not call to find them... I was lost in quiet. I thought that I would eventually run into them somewhere by the end of the day, which we did. Best feeling." It appears that in less serious situations, or where specific a priori arrangements for contact and safety communication concerns have been enacted, then the spirit of dead zone experiential spontaneity and no contact is appreciated by the more adventurous.

Immediacy versus connectedness tension: A recurring theme from many respondents was the nature of contemporary, technology influenced interaction. Much information was provided on the subtle ways in which new social norms about communication are developing around the digitally based communication. Matt reported: "Recently I actually sent my wife a (phone) message when we were present with friends because she was not responsive She was so focussed on what she was on. She snapped out of it and she's been pretty good ever since." Taking away the connectedness was seen as potentially very stressful for some respondents. Trish reported her behavioural response quite simply: "I cry". The dead zone poses challenges for those deeply embedded in using social media and mobile technologies. When asked what skills they thought were diminished by high levels of technology dependency, respondents noted orientation skills, hand writing skills and especially communication skills. Some parents noted the inability of teenage children in a dead zone "to go out, use their creativity and imagination". In particular the abilities to find one's own entertainment, to focus on those in one's immediate presence and to engage in sustained conversation were marginally confronting to some but deeply rewarding to others. A strong theme here was the superficiality of some friendships. Harriet noted that the new technologies had their own skills and suggested that in composing a text for example it is possible to "craft 
a comment rather than have to reply immediately in a face to face encounter". The notion that dead zone tourism offers the opportunity for an introductory or refresher courses in how to engage with the immediate presence of others in a sustained way is a potential part of its positive experiential contribution.

\section{DISCUSSION}

The participants in the focus group interviews provided much information. Importantly, they engaged in the discussion processes concerning dead zone tourism with considerable enthusiasm. This active engagement immediately confirmed the broad social significance of the issue of how to manage one's technology-supported connections while on holidays. The sustained enthusiasm also supported the value of researching and identifying experiential dimensions for the dead zones. The overriding and well supported conclusion from the results section is that contemporary technology produces technology-induced tension for holidays in general and for dead zone tourism in particular.

The focus group results and the identified themes confirm several of the suggestions in the literature on vacation based technology use. Quite specifically, the identification of social communication demands on holiday makers has also been observed by White and White (2007), Hottola (2004), Gretzel (2010) and Sigala (2012). The dead zone focus group respondents observed that the manipulation of one's excuses for less than usual contact is well served by being able to stipulate that there they were "unplugged". The work related electronic leash has been identified in studies by Joyce (2008) and Porter and Kakabadse (2006), and is now clearly relevant to work demands during holiday time. This hold of the workplace on the contemporary worker through technology and ongoing communication contact can also be seen as justifiably able to be broken when vacationers move into dead zones.

The value of technology in providing a safety net for travellers has been pivotal in changing the nature of tourism. As Hottola (2004) argued, when tourists are genuinely disconnected from their home world the experiences can be varied; sometimes rewarding, sometimes transformative and occasionally threatening. The dead zone tourism space restores some of 
the confronting adventure of earlier periods in tourism but it is notable that this advantage is resisted and has some strong negative emotional consequences for sub-sets of travellers.

The concern with safety and the reported distress at being in a dead zone as evidenced by some travellers who worried about being off-line (cf. Shu and Wang, 2011) can arguably be linked to one of the oldest challenges tourists face in a new setting: what is there to do, how can I entertain myself and how do I interact with others (Pearce, 2005: 113-134). The notable positive benefit reported by some focus group members on these issues was the stimulus provided by dead zones to be "in the moment"; that is use one's social skills, conversational abilities and sense of initiative to serve the goals of enjoying the dead zone time, space and immediate companions.

It was suggested in the literature review section that the analyses of experience which are being developed by tourism and leisure researchers might be able to be applied in a post -hoc fashion to review the participants' reactions to dead zone tourism. As suggested earlier, the term experience is now a core expression in tourism study (Morgan et al., 2010). Historical as well as contemporary studies suggest that the compass of our interest in experiences includes tourists' sensory systems and emotions, their attitudes and their understanding as well as how they interact with others and move in space and time. One metaphorical way to grasp the richness of the experience concept is to liken it to the music produced by an orchestra. There are multiple contributing sections, each of which has its own elements. These sources of influence contribute different component parts at different times to achieve the full musical (or experiential) effect. In the tourists' experiential world the contributing components are the sensory inputs, the affective and emotional reactions, the cognitive abilities to react to and understand the setting, the actions undertaken and the relevant relationships which define the participants' world. Select elements are sometimes more powerful than others such as when emotion dominates a visitors' experience to a dark, tragedy filled tourism site. Nevertheless the totality of the full experience will also include behavioural, sensory cognitive and relationship contributions. The sources of this way of thinking about experience derive from the work of Ryan (1997), Ashcroft (2000), Schmitt (2003), Baerenholdt et al. (2004), Peters (2005), Pearce (2005), and some of the work of Cutler and Carmichael (2010). 
These contributing components of the full orchestra of experience can be considered in isolation for the purposes of analysis, while bearing in mind that for the tourists there is an integrated totality to how they react to dead zones. The sensory component of the dead zone experience can be considered first. The experience of being unplugged involves several strong sensory elements or more precisely the absence of highly familiar sensory inputs. Those who use their mobile phones a lot, as well as those who spend large amounts of on screen time, have familiar sensory routines involving tactile, auditory and visual elements. The absence of these sensory elements may be viewed as akin to a minor form of sensory deprivation and the further investigation of the influence of these cues and the reward systems they generate for users may lead to explanations about the high commitment to mobile technologies highlighted in the focus group data. Opponent process theory used to explain certain forms of addiction as well as the power of partial reinforcement in shaping behaviour would appear to be promising routes of psychological inquiry to explore these strong sensory experiences and compelling behaviours (Martin et al., 2007).

Experiential elements of an affective and emotion based nature are also implicated in the dead zone tourism experience. The data collected from the focus groups suggested that anxiety, a heightened emotional concern for others, and a feeling of loss and threat were not uncommon in thinking about and experiencing being in a dead zone. As the study of emotions in tourism experience blossoms more generally (cf. Zins, 2002; Coghlan and Pearce, 2010), the study of emotional reactions to being in a dead zone may help crystallize the understanding of the emotional range of tourist experiences. The cognitive elements of being in a dead zone are also not trivial. The ability to understand how to behave and respond to the novel experience of being a without one's usual technology links was one of the themes identified. These cognitive implications are connected with establishing or reaffirming key behavioural repertoires such as really talking to those present and forging ways to orient, entertain and embellish one's experience without technology. The final component of the experiential repertoire suggested by the orchestrated approach to experience is that of relationship influences. Both through social links and work based relationships this component of the tourist experience in dead zones were highlighted. In concert therefore, the dead zone tourism study reported here suggests that the experience of being unplugged has multi-faceted experiential elements, all of which underpin the tension categories already outlined. 
Taking a broader view, the label dead zone tourism used throughout this paper is, arguably, a potentially negative label for tourism businesses and regions. To some, it may suggest a form of dark tourism, the absence of anything to do in the location or, worse still, a dangerous and threatening setting. As the advantages of being disconnected from mobile and internet links emerge from research efforts and attempts to create business from these results develop, it is unlikely that the term dead zone will be a commercially appealing one for promotional purposes. It is likely to be replaced with a more appealing set of labels such as unplugged, truly free, fully present and without a leash. The concept of being "unplugged" is already receiving some attention in the commercial world with the term "black hole resort" being used to promote locations where there is "no mobile reception, (and) no midnight Blackberry beeps" (Qantas Magazine April 2012, 134). Similarly there are positive statements asserting the value of being off-line: "The greatest luxury of the 21st century will be dropping off the grid" (Travel + Leisure, October 2011). Irrespective of the future directions in terminology engineered by marketing personnel, the further analysis of tourism in these special regions in contemporary society can help illuminate the nature of why we travel and the centrality of the connections between those holiday experiences and everyday life.

\section{REFERENCES}

Ashcroft, F. (2000) Life at the Extremes: The Science of Survival. London: Flamingo. Baerenholdt, J., Haldrup, M., Larsen, J., \& Urry, J. (2004). Performing tourist places. Aldershot, Hants; Ashgate.

Berry, J. W. (1999). Emics and etics: A symbiotic conception. Culture \& Psychology, 5, 165171.

Cohen, E. (1979). Rethinking the sociology of Tourism. Annals of Tourism Research, 6(1), 18-35.

Coghlan, A., and Pearce, P.L. (2010) Tracking affective components of satisfaction. Journal of Tourism and Hospitality Research, 10 (1), 1-17.

Cutler, S.Q. \& Carmichael, B.A. (2010) The dimensions of the tourist experience. In M.

Morgan, P. Lugosi and J.R. Brent Ritchie (Eds.). The Tourism and Leisure Experience (pp. 326). Bristol: Channel View.

De Crop, A. (2004). Trustworthiness in qualitative tourism research. In J. Phillimore, \& L. Goodson (Eds.), Qualitative research in tourism (pp. 156-169). London: Routledge.

Diener, E, \& Biswas-Diener, R. (2008). Happiness: Unlocking the mysteries of psychological wealth. Oxford: Blackwell. 
Filep, S. (2012) Positive psychology and tourism. In M. Uysal, R. Perdue and M.J. Sirgay (Eds.) Handbook of Tourism and Quality of Life research. (pp. 31-50). London: Springer.

Flick, U. (2006). An introduction to qualitative research. (Third edition) London: Sage.

Gomm, R. (2004). Social research methodology. Bristol: Palgrave-MacMillan.

Graburn, N.H. (1989). Tourism: The Sacred Journey. In V Smith (Ed.), Hosts and Guests: The Anthropology of Tourism, 2nd ed., pp. 17-32. Philadelphia: U of Pennsylvania Press.

Gretzel, U. (2010). Travel in the Network: Redirected Gazes, Ubiquitous Connections and New Frontiers. In M. Levina \& G. Kien (Eds.). Postglobal Network and Everyday Life, 4158. New York: Peter Lang.

Grüsser, S M, Thalemann, R, Albrecht, U, \& Thalemann, C.N . (2005). Excessive computer usage in adolescents - a psychometric evaluation. Wiener Klinische Wochenschrift, 117(5), 188-195.

Hottola, P. (2004). Culture confusions: Intercultural adaptation in tourism. Annals of Tourism Research 31(2), 447-466.

Jansson, A. (2007). A sense of tourism: New media and the dialectic of encapsulation/decapsulation. Tourist Studies, 7(1), 5-24.

Jennings, G. (2010). Tourism Research (Second edition). Milton Qld: Wiley

Joyce, J. F. (2008). Internet Addiction: Recognition and Interventions. Archives of Psychiatric Nursing, 22(2), 59-60.

Kozak, M. (2001). A critical review of approaches to measure satisfaction with tourist destinations. In J. A. Mazanec, G. Crouch, J. R. Brent Ritchie \& A. Woodside (Eds.), Consumer psychology of tourism hospitality and leisure, Vol. 2, pp. 303-320. Wallingford: CABI.

Krueger, R. and M. Casey (2000). Focus Groups - A Practical Guide for Applied Research ( ${ }^{\text {rd }}$ edn.). London: Sage Publications Inc.

Langer, E. J. (2009). Counterclockwise: Mindful Health and the Power of Possibility. New York: Ballantine Books.

Martin, G. N., N. R. Carlson, \& W. Buskit (2007). Psychology (3rd ed.). Harlow, England: Pearson.

Morgan, M., Lugosi, P. and Brent Ritchie, J. R. (Eds.) (2010) The Tourism and Leisure experience: Consumer and Managerial Perspectives. Bristol: Channel View.

Morris, I. (2010). Why the West rules - for now. London: Profile Books.

Niblo, D. M., and Jackson, M. S. (2004). Model for combining the qualitative emic approach with the quantitative derived etic approach. Australian Psychologist, 39(2), 127-133.

Noe, F.P. (1999). Tourism service satisfaction. Champaign, Illinois: Sagamore.

Pearce, P.L. (2005). Tourist behaviour Themes and Conceptual Schemes. Clevedon: Channel View:

Pearce, P.L. (2011). Tourist behaviour and the Contemporary World. Bristol: Channel View.

Peters, T. (2005) Essentials Design. London: DK.

Pisani, E. (2008). The Wisdom of Whores. London: Granta. 
Porter, G \& Kakabadse, N. (2006). HRM perspectives on addiction to technology and work. J. of Management Development, 25(6), 535-560.

Prensky, M. (2001). Digital natives, Digital Immigrants Part 1. On the Horizon, 9, 1-5.

Rabiee, F. (2004). Focus group interview and data analysis. Proceedings of the Nutrition Society, 63, 655-660.

Rossiter, J. (2011) Measurement for the Social Sciences - The C-OAR-SE Method and Why it Must Replace Psychometrics. Springer: New York.

Ryan, C. (1995). Researching Tourist Satisfaction: Issues, Concepts, Problems. London: Routledge.

Ryan, C. (1997). The Tourist Experience: A New Introduction. New York: Cassell.

Ryan, C. (2000). From the psychometrics of SERVQUAL to sex: Measurements of tourist satisfaction. In Pizam, A \& Mansfeld, Y (Eds.), Consumer behavior in travel and tourism, pp. 267-286. New York: The Haworth Hospitality Press.

Salon.com (2010). No more vacation: How technology is stealing our lives. Accessed online (Jan. 3, 2012) at http://www.salon.com/2010/07/16/tech_exhaustion/.

Schmitt, B.H. (2003). Customer Experience Management. Hoboken, NJ: John Wiley \& Sons.

Seligman, M.E.P., Steen, T., Park, N. \& Peterson, C. (2005). Positive psychology progress:

Empirical validation of interventions. American Psychologist, 60 (5), 410-421.

Shu, Q, Tu, Q, \& Wang, K. (2011). The Impact of Computer Self-Efficacy and Technology Dependence on Computer-Related Technostress: A Social Cognitive Theory Perspective. Int. J. of Human-Computer Interaction, 27(10), 923-939.

Sigala, M. (2012).Web 2.0 and Customer involvement in new service development: a framework, cases and implications in tourism. In M. Sigala, E, Christou and U. Gretzel ( Eds.). Social Media in Travel, Tourism and Hospitality. (pp.25-38). Farnham, Surrey: Ashgate.

Tribe, J. (Ed.) (2009) Philosophical issues in tourism. Bristol: Channel View.

Turel, O, Serenko, A, \& Bontis, N. (2011). Family and work-related consequences of addition to organizational pervasive technologies. Information \& Management, 48(2-3), 8895.

Turel, O., Serenko, A. \& Giles, P. (2011). Integrating technology addiction and use: An empirical investigation of online auction users. MIS Quarterly, 35(4), 1043-A1018.

Turner, U. and Turner, E. (1978). Image and Pilgrimage in Christian Culture. New York: Columbia University Press.

Tussyadiah, I. \& Fesenmaier, D. R. (2009). Mediating Tourist Experiences: Access to Places via Shared Videos. Annals of Tourism Research, 36(1), 24-40.

Van Egmond, T. (2007). Understanding western tourists in developing countries. Wallingford, Oxon.: CABI.

Van Gennep, A. (1960). The rites of passage. Chicago: University of Chicago Press.

Walle, A. H. (1997). Quantitative versus qualitative tourism research. Annals of Tourism Research, 24(3), 524-536. 
Warner, R. (1999). The emics and etics of quality of life assessment. Social Psychiatry Psychiatr Epidemiol, 34, 117-121.

White, N.R. \& White, P.B. (2007) Home and away: Tourists in a connected world. Annals of Tourism Research, 34, (1), 88-104.

Yoo, K.H., \& Gretzel, U. (2012). Use and Creation of Social Media by Travelers. In Sigala, M., Christou, E., \& Gretzel, U. (Eds.), Social Media in Travel, Tourism and Hospitality (pp.189-206). Brookfield, VT:

Zins, A.H. (2002). Consumption emotions, experience quality and satisfaction: A structural analysis for complainers and non-complainers. Journal of Travel and Tourism Marketing, $12(2), 3-18$ 